\title{
Evaluating Bone Health in Egyptian Children with Forearm Fractures: A Case Control Study
}

\author{
Abeer El-Sakka, ${ }^{1}$ Cristina Penon, ${ }^{2}$ Adham Hegazy, ${ }^{1}$ \\ Salwa Elbatrawy, ${ }^{3}$ Amr Gobashy, ${ }^{1}$ and Alvaro Moreira ${ }^{2}$ \\ ${ }^{1}$ Department of Pediatrics, Ain Shams University Medical School, Cairo, Egypt \\ ${ }^{2}$ Department of Pediatrics, University of Texas Health Science Center, San Antonio, TX, USA \\ ${ }^{3}$ Department of Biology, National Research Center, Cairo, Egypt \\ Correspondence should be addressed to Abeer El-Sakka; drasakka@gmail.com
}

Received 15 April 2016; Revised 28 July 2016; Accepted 11 August 2016

Academic Editor: F. J. Kaskel

Copyright (C) 2016 Abeer El-Sakka et al. This is an open access article distributed under the Creative Commons Attribution License, which permits unrestricted use, distribution, and reproduction in any medium, provided the original work is properly cited.

\begin{abstract}
Objective. To determine the likelihood of vitamin D deficiency and low bone mineral density in Egyptian children with forearm fractures. Methods. A case control study of 46 children aged 3 to 10 years with or without forearm fractures. Validated questionnaires were used to assess calcium and vitamin D intake as well as sun exposure. Serum calcium, phosphorus, alkaline phosphatase, and 25hydroxy-vitamin D were collected. Bone mineral density was evaluated using dual-energy X-ray absorptiometry. Results. Compared to the Control group, calcium and vitamin D intake was lower in the Cases group $(p=0.03)$. Cases had higher Body Mass Index than Controls, $p=0.01$. Children in the Cases group had lower mean serum calcium values $8.3 \pm 1.4$ compared to $9.3 \pm 1.1$ in Controls $(p=0.01)$. Alkaline phosphatase was higher in Cases $265 \pm 65.8$ than Controls $226 \pm 54.6(p=0.03)$. Vitamin D and bone mineral density scores were significantly lower in the Cases group $(p<0.05)$. Conclusion. Our data shows an increased rate of vitamin D deficiency and decreased bone mineral density in Egyptian children with forearm fractures.
\end{abstract}

\section{Introduction}

Forearm fractures are the most common childhood fracture that presents to the emergency room in the United States [1]. Despite improvements in many childhood conditions, the incidence of forearm fractures in pediatric patients has increased throughout the last few decades. More concerning, children with a history of a forearm fracture have a higher risk of entering adulthood with decreased peak bone mass [2]. Although most research efforts have focused on fractures in late adulthood, there is emerging evidence that fractures in childhood may be the initial insult that leads to lifelong bone fragility [3].

In neonates and children, vitamin $\mathrm{D}$ deficiency has been directly linked to suboptimal bone mineralization and adverse conditions such as rickets and short stature [4-6].

Specifically, vitamin D is an important regulator of calcium $(\mathrm{Ca})$ and phosphorus $(\mathrm{P})$ homeostasis, the minerals necessary for bone formation [7]. Through its interactions in the kidney and intestine, activation of vitamin D stimulates bone mineralization $[8,9]$. Furthermore, by the time children enter adolescence $40 \%$ of their peak bone mass has been accrued [10].

Dual-energy X-ray absorptiometry (DXA) imaging is a widely available clinical tool used in adults to diagnose osteoporosis, predict fracture risk, and monitor response to therapy [11]. With increased concern for future bone health, investigations using DXA in the pediatric population are becoming an area of high research interest $[12,13]$. Similar to adults, DXA is the preferred imaging modal to measure bone mineral density (BMD) and bone mineral content in children due to the precise results, minimally invasive approach, and little exposure to radiation [14].

Multiple studies have demonstrated an association between vitamin $\mathrm{D}$ deficiency and fracture risk in children [14-17]. However, few studies have correlated vitamin D deficiency with BMD, fracture risk, and laboratory markers of bone health [18]. To our knowledge, no study has evaluated 
TABLE 1: Calcium and vitamin D intake questionnaire.

\begin{tabular}{lcc}
\hline Intake question (weekly basis) & Approximate calcium content (mg) & Approximate vitamin D content (IU) \\
\hline $\begin{array}{l}\text { How often does your child drink milk? } \\
\text { How often does your child eat. . }\end{array}$ & 1 cup whole milk: 246 & Vitamin D fortified cup of milk: $115-124$ \\
Yogurt? & 6 ounces nonfat yogurt: 258 & Fortified with $20 \%$ for daily value (DV) \\
Cheese? & 1 ounce cheese: 202 & 1 ounce cheese: 6 \\
Fish? & & Salmon, cooked, 3 ounces: 794 \\
Eggs? & 2 sardines, canned in oil, drained: 46 \\
Liver? & 1 whole egg: 25 \\
Does your child take Ca or vitamin D supplementation? & Varies & Liver, beef, cooked, 3.5 ounces: 46 \\
\hline
\end{tabular}

Questionnaire modified from Greer et al. [19]. Approximations obtained from US Department of Agriculture Nutrient Data Laboratory [20].

vitamin D status, BMD, and serologic markers of bone health in children from a developing country presenting to the emergency room with a forearm fracture.

Therefore, the aim of this study is to determine the prevalence of vitamin D deficiency and its effects on BMD in Egyptian children presenting with forearm fractures. We hypothesize that Egyptian children with forearm fractures have lower serum 25-hydroxy-vitamin D levels and BMD $z$-scores compared to children without forearm fractures. We also examined the relationship between vitamin $\mathrm{D}$ and serologic markers of bone health.

\section{Methods}

2.1. Study Center and Subjects. This study was conducted at Ain Shams University Hospital (ASUH) in Cairo, Egypt.

The Ethical Committee of ASUH approved the study which was conducted between December 2012 and June 2013 which corresponds to winter and spring in Egypt. Children between the ages of 3 and 10 years who presented to the Emergency Room at ASUH and had a confirmed radiologic fracture to the radius, ulna, or both were included in the study as Cases. Controls were children who had forearm pain or trauma but did not have radiographic evidence of forearm fracture. They were matched for gender and age to Cases.

Children were excluded from the study if they had a previous history of fractures, prolonged immobilization, or chronic use of antiepileptic drugs or glucocorticoids. Children with chronic illnesses that may interfere with bone health such as kidney disease or intestinal malabsorption were also excluded.

2.2. Study Design. This was a prospective case control study in children with or without forearm fractures to determine their vitamin D status and its impact on BMD. Calcium and vitamin $\mathrm{D}$ intakes were assessed via a modified food questionnaire [19]. Intake data was categorized into adequate, suboptimal, and low intake using the US Department of Agriculture Nutrient Database for Standard Reference [20] (Table 1). Extent of sun exposure was also categorized into daily, weekly, or no sun exposure [21].
2.3. Dual Energy X-Ray Absorptiometry (DXA) Measurements and Anthropometrics. All total body BMD measurements were performed using a Hologic Discovery $\mathrm{Ci} / \mathrm{Wi}$ bone densitometer (Hologic ${ }^{\mathrm{TM}}$, Bedford, Massachusetts, USA) by a certified radiology technologist. Measurement results were obtained using Hologic's internal pediatric data software which takes into account patient's height, weight, and gender. Reported values were given as standard deviation scores $(z$ scores). A $z$-score of zero was equivalent to the mean, while a $z$-score between -1 and +1.5 was equivalent to values of one standard deviation below and 1.5 standard deviations above the mean, respectively. Per the International Society for Clinical Densitometry, a $z$-score less than or equal to 2 is defined as "low bone mass or bone mineral density" [22]. All measurements were performed and analyzed by the same individual.

2.4. Serologic Markers of Bone Health. The following laboratory tests were obtained in all subjects:

(1) Serum Ca was measured via colorimetric assay (Ocresolphthalein complexone method) using SP120 autochemistry analyzer (Spectrum Diagnostics ${ }^{\mathrm{TM}}$, Cairo, Egypt). Normative values were provided by the manufacturer and were between 9.2 and $11 \mathrm{mg} / \mathrm{dL}$ in children of $4-16$ years and 7.2 and $11.2 \mathrm{mg} / \mathrm{dL}$ in children of 4 weeks -3 years.

(2) Serum $P$ was measured by one-step colorimetric endpoint method without deproteinization by Vitro Scient Company ${ }^{\mathrm{TM}}$, Cairo, Egypt. Expected values were $4.4-5.5 \mathrm{mg} / \mathrm{dL}$ in children of 2-16 years.

(3) Serum alkaline phosphatase (ALP) was measured by one-step colorimetric endpoint (Teco Diagnostics ${ }^{\mathrm{TM}}$, Anaheim, CA, USA). Coefficient of variance for this test is $3.1 \%$ to $4.2 \%$. Normal values stated by the manufacturer include 32-92 IU/L.

(4) Serum vitamin D measurements were analyzed using 25-hydroxy-vitamin D ( ${ }^{125}$ I RIA kit by DiaSorin Company $^{\mathrm{TM}}$, Still Water, MN, USA). This assay uses direct competitive chemiluminescence using coated magnetic microparticles. Coefficient of variance for 
TABLE 2: Subject characteristics and calcium and vitamin D intake.

\begin{tabular}{lccc}
\hline & Controls $(n=23)$ & Cases $(n=23)$ & \\
\hline Subject characteristics & & & \\
Age, years & $7.7 \pm 1.7$ & $6.7 \pm 2.3$ & 0.08 \\
Weight, $\mathrm{kg}$ & $25.6 \pm 5.1$ & $22.3 \pm 6.0$ & 0.06 \\
Height, cm & $123.7 \pm 10.1$ & $116.8 \pm 13.3$ & 0.06 \\
Male gender & $14(60.8)$ & $14(60.8)$ & $15.64 \pm 1.84$ \\
Body mass index $\left(\mathrm{kg} / \mathrm{m}^{2}\right)$ & $16.69 \pm 0.94$ & & 0.01 \\
Calcium and vitamin D intake & & $11(47.8)$ \\
$\quad$ Adequate & $11(47.8)$ & $5(21.7)$ \\
$\quad$ Suboptimal & $11(47.8)$ & $7(30.4)$ \\
$\quad$ Low & $1(4.3)$ & $10(43.5)$ \\
Sun exposure & $15(65.2)$ & $9(39.1)$ \\
$\quad$ Daily & $8(34.8)$ & $4(17.4)$ \\
Weekly & 0 & $0.03^{*}$ \\
$\quad$ None & &
\end{tabular}

Results are expressed as mean \pm standard deviation or $n(\%)$.

$*$ signifies $p$ value $\leq 0.05$.

intraruns using this test is between $4.8 \%$ and $7.7 \%$. The laboratory reference range is $30-100 \mathrm{ng} / \mathrm{mL}$.

2.5. Vitamin D Categorization. Categorization of $25-\mathrm{OH}-$ vitamin $\mathrm{D}$ results followed the recommendations from the American Academy of Pediatrics [23]:

(i) Sufficiency $>20-100 \mathrm{ng} / \mathrm{mL}$.

(ii) Insufficiency $>15-20 \mathrm{ng} / \mathrm{mL}$.

(iii) Deficiency $\leq 15 \mathrm{ng} / \mathrm{mL}$.

(iv) Severe Deficiency $\leq 5 \mathrm{ng} / \mathrm{mL}$.

2.6. Statistical Analysis. Continuous data was analyzed using Student's $t$-test, and categorical data was analyzed using chisquared analysis, or Fisher's exact test where appropriate. A $p$ value $\leq 0.05$ was considered statistically significant. STATA v.13 (Microsoft Corporation ${ }^{\mathrm{TM}}$, College Station, Texas, USA) was used to analyze data.

\section{Results}

3.1. Subjects. A total of 46 children were enrolled during the study period. There were 23 patients with confirmed forearm fractures in the Emergency Room at ASUH. The mean age was $7.2 \pm 2.0$ years, and $61 \%$ of subjects were boys. The demographic data is summarized in Table 2.

3.2. Calcium and Vitamin D Intake and Sun Exposure. Overall, half of the participants in the study had suboptimal or low intake of vitamin D and Ca. However, 30\% of the subjects in the Cases group reported low vitamin $\mathrm{D}$ and $\mathrm{Ca}$ intake compared to $4 \%$ in the Controls group ( $p \leq 0.05$ ). Ninetyone percent of subject had reported either daily or weekly sun exposure. Four children with no reported sun exposure had forearm fractures (Table 2).
3.3. Calcium, Phosphorus, Alkaline Phosphatase, and Vitamin $D$ Levels. Values for all serum Ca labs drawn ranged from 5.5 to $11.3 \mathrm{mg} / \mathrm{dL}$ with a mean of $8.8 \mathrm{mg} / \mathrm{dL}$. Serum ALP levels drawn ranged from 160 to $400 \mathrm{IU} / \mathrm{L}$, with a mean of $245 \mathrm{IU} / \mathrm{L}$. Children with fractures had statistically significant lower serum Ca values $(p \leq 0.05)$ and higher serum ALP levels when compared with the Controls group $(p \leq 0.05)$. Vitamin D measurements ranged from 1.3 to $100 \mathrm{ng} / \mathrm{mL}$ with a mean of $38 \mathrm{ng} / \mathrm{mL}$. Our study had one patient that was vitamin $\mathrm{D}$ deficient and eight patients with severe vitamin $\mathrm{D}$ deficiency. The four subjects in the Cases group with no reported sun exposure all had severe vitamin D deficiency. Data is summarized in Table 3.

3.4. Bone Mineral Density. The mean $z$-score in Cases was $-0.19 \pm 1.99$ and $0.3 \pm 1.04$ in the Controls group $(p=0.3)$. The 7 Cases with severe vitamin $\mathrm{D}$ deficiency had a $z$-score $\leq-2$ (low bone mineral density). The single patient in the Controls group that had severe vitamin D deficiency had a $z$-score of -1.9. Graphic representation is seen in Figure 1.

3.5. Bone Serologic Markers in Relation to Vitamin D Level. As shown in Figure 2, serum Ca had correlations with serum 25$\mathrm{OH}$-vitamin D levels $(p \leq 0.01)$. There were no significant correlations found between serum 25-OH-vitamin D and phosphorus or alkaline phosphatase. No association was found between Vitamin D and gender, age, or Body Mass Index (BMI).

\section{Discussion}

This study found a high percentage of severe vitamin D deficiency in Egyptian children with forearm fractures. Furthermore, this study demonstrates that $25-\mathrm{OH}$-vitamin $\mathrm{D}$ is an important marker of bone mineralization in children with fractures. 
TABLE 3: Vitamin D status and serum calcium, phosphorus, and alkaline phosphatase levels.

\begin{tabular}{lccc}
\hline & Controls $(n=23)$ & Cases $(n=23)$ & $p$ value \\
\hline Calcium, mg/dL & $9.3 \pm 1.1$ & $8.3 \pm 1.4$ & $0.01^{*}$ \\
Phosphorus, mg/dL & $4.0 \pm 0.7$ & $3.7 \pm 0.8$ & 0.21 \\
ALP, IU/L & $226 \pm 54.6$ & $265 \pm 65.8$ & $0.03^{*}$ \\
$25-$ OH vitamin D categorized & & & \\
Sufficient & $18(78.3)$ & $13(56.5)$ \\
Insufficient & $4(17.4)$ & $2(8.7)$ \\
Deficiency & $0(0)$ & $1(4.3)$ \\
Severe & $1(4.3)$ & $7(30.4)$ \\
\hline
\end{tabular}

Results are expressed as mean \pm standard deviation or $n$ (\%).

$*$ signifies $p$ value $\leq 0.05$.

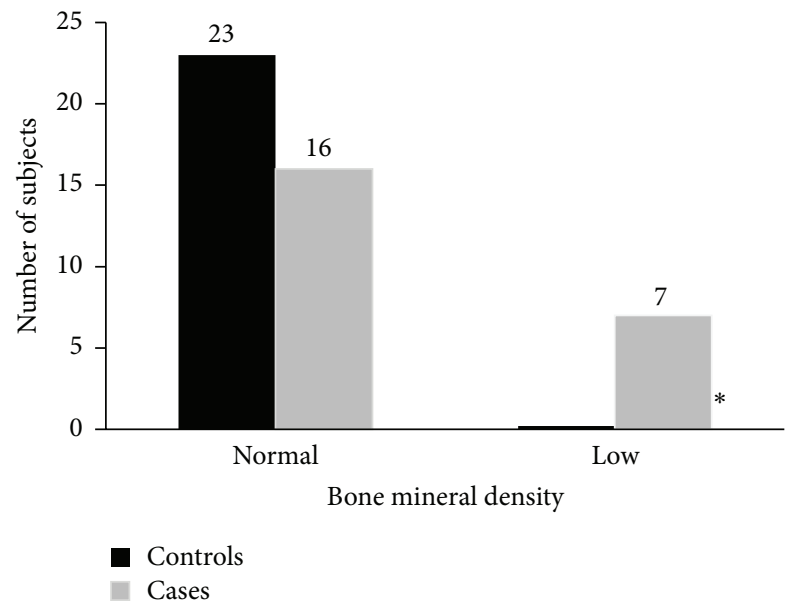

Figure 1: Bone mineral density in Cases and Controls. $*$ signifies $p$ value $\leq 0.05$.

Our findings are in agreement with studies by Ryan et al. $[17,18]$ who found that a significant proportion of children with forearm fractures were vitamin $\mathrm{D}$ insufficient $[21,22]$. In our study, $33 \%$ of children had vitamin D insufficiency. Similarly, their studies describe a direct association between 25-OH-vitamin D levels and BMD $z$-scores. The patients in our study had overall lower $z$-scores compared to the subjects in their study (.06 z-score versus $0.8 z$-score). Collecting dietary calcium and vitamin $\mathrm{D}$ intake and sunlight exposure allows us to infer that the differences in $z$-scores may be secondary to the suboptimal/low nutritional status (50\%) of the Egyptian children, as well as the lack of sun exposure $[24,25]$.

Vitamin D synthesis from the sun is considered an important source of vitamin D [26]. Our study included four individuals with no sun exposure who were found to have vitamin $\mathrm{D}$ deficiency as well as low BMD measurements. This highlights the importance of sun light exposure in bone health in children. This was recently emphasized by studies comparing indoor and outdoor training in athletes and found significant lower Vitamin D levels in those with indoor training [27]. Our study adds to the growing literature that supports the importance of outdoor sunlight exposure for children. Studies as early as the industrial revolution

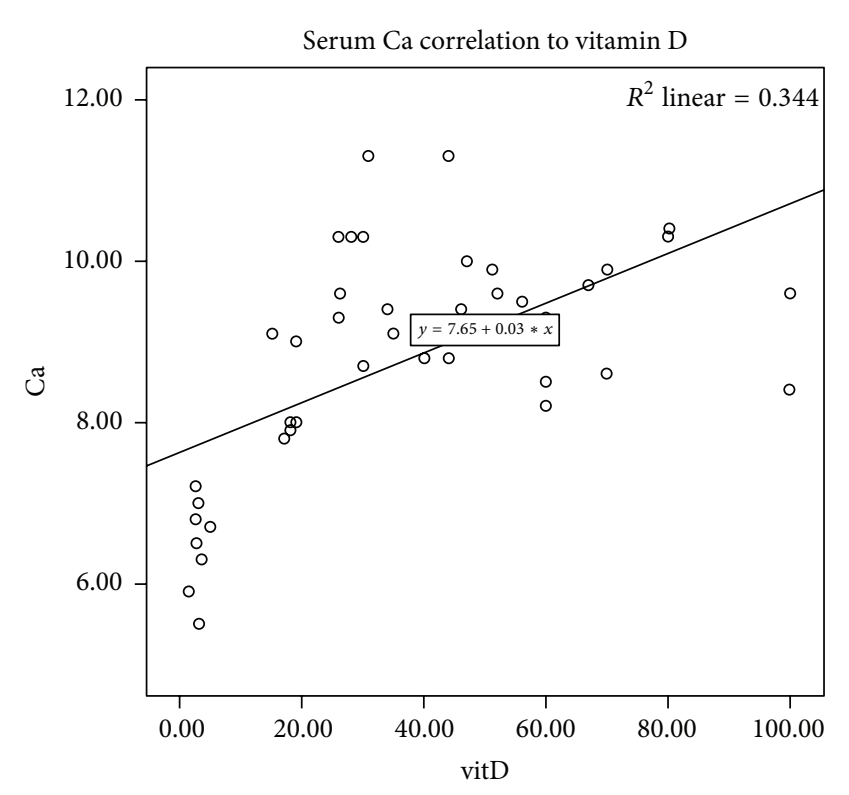

FIgURE 2: Serum calcium correlation to vitamin D. ${ }^{*} R^{2}=0.334, p<$ 0.01 .

in Europe have demonstrated bone deformities in children living in the inner cities exposed to minimal sun exposure [28].

This study showed a significant correlation between serum calcium levels and vitamin D. Vitamin D plays an important role in calcium homeostasis through its absorption in the intestine and kidney. In cases of poor calcium intake or absorption, 1,25-hydroxyvitamin D mobilizes Ca from bone thereby inhibiting mineral deposition into the osteoid matrix $[29,30]$. In postmenopausal women, low levels of serum calcium are frequently associated with increased risk for fractures [31]. Furthermore, poor calcium intake and distal forearm fractures during childhood are strong predictors of skeletal fragility in adulthood $[32,33]$.

In agreement with our results Michałus et al. found lower mean values of BMD $z$-scores with higher alkaline phosphatase levels in children who had multiple bone fractures [34]. In our study, although serum ALP levels were within normal reference values, they were significantly higher 
in those with fractures. The importance of serum calcium and alkaline phosphatase as markers for abnormal bone health and osteomalacia has been described in the study by Peach et al. [35]. In their study, they found elevated plasma alkaline phosphatase and hypocalcemia in $48 \%$ of patients diagnosed histologically as having osteomalacia. Moreover, alkaline phosphatase measurements have recently been recommended as a screening tool for osteomalacia [36]. Also, ALP has been described as a screening tool for preterm newborns at risk for metabolic bone disease, especially when accompanied with low serum phosphate [37].

We found that Cases have significant higher Body Mass Index (BMI) than Controls, $p=0.01$. This supports other studies which found that high adiposity is associated with increased risk of forearm fractures in children [38].

This study is important because children who develop vitamin $\mathrm{D}$ deficiency can potentially have life-long complications. Considering that peak bone mass is reached by the end of the second decade of life, children with early fractures have a high probability of future fracture and more concerning osteoporosis later in life [39, 40]. Thus improvement in awareness of bone health in the pediatric population can directly impact on quality of life. Although pubertal status is important in evaluating BMD, our subjects were in the age between 3 and 10 years which is less than the optimal age of puberty in Egyptian children [41].

A major limitation of this study is the small number of subjects included in the study. Larger studies are necessary to corroborate our findings.

\section{Conclusions}

This study demonstrates that vitamin D insufficiency/deficiency is common among Middle Eastern children. It points out the importance of assessing vitamin D status in children with fractures.

\section{Competing Interests}

The authors declare that they have no competing interests.

\section{Acknowledgments}

This work was supported by 4KL2TR001118-04 awarded to Alvaro Moreira.

\section{References}

[1] S. M. Naranje, R. A. Erali, W. C. Jr. Warner, J. R. Sawyer, and D. M. Kelly, "Epidemiology of pediatric fractures presenting to emergency departments in the United States," Journal of Pediatric Orthopaedics, vol. 36, no. 4, pp. e45-e48, 2016.

[2] S. Khosla, L. J. Melton III, M. B. Dekutoski, S. J. Achenbach, A. L. Oberg, and B. L. Riggs, "Incidence of childhood distal forearm fractures over 30 years: a population-based study," The Journal of the American Medical Association, vol. 290, no. 11, pp. 14791485, 2003.

[3] E. M. Clark, A. R. Ness, and J. H. Tobias, "Bone fragility contributes to the risk of fracture in children, even after moderate and severe trauma," Journal of Bone and Mineral Research, vol. 23, no. 2, pp. 173-179, 2008.

[4] C. L. Wagner and F. R. Greer, "Prevention of rickets and vitamin D deficiency in infants, children, and adolescents," Pediatrics, vol. 122, no. 5, pp. 1142-1152, 2008.

[5] M. Kassab, I. Shaban, K. Mohammad, and D. K. Creedy, "Prevalence of hypovitaminosis D among jordanian healthy infants: a descriptive cross sectional study," Journal of Pediatric Nursing, vol. 31, no. 2, pp. e119-e125, 2016.

[6] A. Moreira, M. February, and C. Geary, "Parathyroid hormone in neonates," Journal of Paediatrics and Child Health, vol. 49, no. 1, pp. E12-E16, 2013.

[7] M. Halfon, O. Phan, and D. Teta, "Vitamin D: a review on its effects on muscle strength, the risk of fall, and frailty," BioMed Research International, vol. 2015, Article ID 953241, 11 pages, 2015.

[8] A. Moreira, L. Swischuk, M. Malloy, D. Mudd, C. Blanco, and C. Geary, "Parathyroid hormone as a marker for metabolic bone disease of prematurity," Journal of Perinatology, vol. 34, no. 10, pp. 787-791, 2014.

[9] S. Christakos, P. Dhawan, A. Porta, L. J. Mady, and T. Seth, "Vitamin D and intestinal calcium absorption," Molecular and Cellular Endocrinology, vol. 347, no. 1-2, pp. 25-29, 2011.

[10] D. A. Bailey, H. A. McKay, R. L. Mirwald, P. R. E. Crocker, and R. A. Faulkner, "A six-year longitudinal study of the relationship of physical activity to bone mineral accrual in growing children: the University of Saskatchewan Bone Mineral Accrual Study," Journal of Bone and Mineral Research, vol. 14, no. 10, pp. 16721679, 1999.

[11] D. Marshall, O. Johnell, and H. Wedel, "Meta-analysis of how well measures of bone mineral density predict occurrence of osteoporotic fractures," British Medical Journal, vol. 312, no. 7041, pp. 1254-1259, 1996.

[12] L. K. Bachrach, I. N. Sills, P. B. Kaplowitz et al., "Clinical report-bone densitometry in children and adolescents," Pediatrics, vol. 127, no. 1, pp. 189-194, 2011.

[13] L. A. Binkovitz and M. J. Henwood, "Pediatric DXA: technique and interpretation," Pediatric Radiology, vol. 37, no. 1, pp. 21-31, 2007.

[14] R. M. Thompson, D. M. Dean, S. Goldberg, M. J. Kwasny, C. B. Langman, and J. A. Janicki, "Vitamin D insufficiency and fracture risk in urban children," Journal of Pediatric Orthopaedics, 2015.

[15] J. J. Contreras, B. Hiestand, J. C. O'neill, R. Schwartz, and M. Nadkarni, "Vitamin D deficiency in children with fractures," Pediatric Emergency Care, vol. 30, no. 11, pp. 777-781, 2014.

[16] N. L. Duplantier and S. Waldron, "Post-traumatic nonunion of the clavicle in a 4 -year-old boy and the importance of vitamin D level testing," Journal of Pediatric Orthopaedics Part B, vol. 25, no. 1, pp. 78-80, 2016.

[17] L. M. Ryan, C. Brandoli, R. J. Freishtat, J. L. Wright, L. Tosi, and J. M. Chamberlain, "Prevalence of vitamin D insufficiency in African American children with forearm fractures: a preliminary study," Journal of Pediatric Orthopaedics, vol. 30, no. 2, pp. 106-109, 2010.

[18] L. M. Ryan, S. J. Teach, S. A. Singer et al., "Bone mineral density and vitamin D status among African American children with forearm fractures," Pediatrics, vol. 130, no. 3, pp. e553-e560, 2012.

[19] F. R. Greer, N. F. Krebs, and American Academy of Pediatrics Committee on Nutrition, "Optimizing bone health and calcium 
intakes of infants, children, and adolescents," Pediatrics, vol. 117, no. 2, pp. 578-585, 2006.

[20] US Department of Agriculture, Agriculture Research Service, US Department of Agriculture Nutrient Data Laboratory, http://www.ars.usda.gov/main/.

[21] A. Al-Othman, S. Al-Musharaf, N. M. Al-Daghri et al., "Effect of physical activity and sun exposure on vitamin D status of Saudi children and adolescents," BMC Pediatrics, vol. 12, article 92, 2012.

[22] A. B. Sopher, I. Fennoy, and S. E. Oberfield, "An update on childhood bone health: mineral accrual, assessment and treatment," Current Opinion in Endocrinology, Diabetes and Obesity, vol. 22, no. 1, pp. 35-40, 2015.

[23] M. Misra, D. Pacaud, A. Petryk, P. F. Collett-Solberg, and M. Kappy, "Vitamin D deficiency in children and its management: review of current knowledge and recommendations," Pediatrics, vol. 122, no. 2, pp. 398-417, 2008.

[24] A. Goulding, J. E. P. Rockell, R. E. Black, A. M. Grant, I. E. Jones, and S. M. Williams, "Children who avoid drinking cow's milk are at increased risk for prepubertal bone fractures," Journal of the American Dietetic Association, vol. 104, no. 2, pp. 250-253, 2004.

[25] L. A. S. Pires, A. C. Araújo de Souza, O. Laitano, and F. Meyer, "Bone mineral density, milk intake and physical activity in boys who suffered forearm fractures," Jornal de Pediatria, vol. 81, no. 4, pp. 332-336, 2005.

[26] V. Saraff and N. Shaw, "Sunshine and Vitamin D," Archives of Disease in Childhood, vol. 101, no. 2, pp. 190-192, 2016.

[27] P. Peeling, S. K. Fulton, M. Binnie, and C. Goodman, “Training environment and vitamin D status in athletes," International Journal of Sports Medicine, vol. 34, no. 3, pp. 248-252, 2013.

[28] M. F. Holick, "Sunlight and vitamin D for bone health and prevention of autoimmune diseases, cancers, and cardiovascular disease," The American Journal of Clinical Nutrition, vol. 80, no. 6, pp. 1678S-1688S, 2004.

[29] G. Carmeliet, V. Dermauw, and R. Bouillon, "Vitamin D signaling in calcium and bone homeostasis: a delicate balance," Best Practice \& Research: Clinical Endocrinology \& Metabolism, vol. 29, no. 4, pp. 621-631, 2015.

[30] N. H. Golden and S. A. Abrams, "Optimizing bone health in children and adolescents," Pediatrics, vol. 134, no. 4, pp. e1229e1243, 2014.

[31] M. M. Formosa and A. Xuereb-Anastasi, "Biochemical predictors of low bone mineral density and fracture susceptibility in maltese postmenopausal women," Calcified Tissue International, vol. 98, no. 1, pp. 28-41, 2016.

[32] S. Amin, L. J. Melton, S. J. Achenbach et al., "A distal forearm fracture in childhood is associated with an increased risk for future fragility fractures in adult men, but not women," Journal of Bone and Mineral Research, vol. 28, no. 8, pp. 1751-1759, 2013.

[33] H. J. Kalkwarf, J. C. Khoury, and B. P. Lanphear, "Milk intake during childhood and adolescence, adult bone density, and osteoporotic fractures in US women," The American Journal of Clinical Nutrition, vol. 77, no. 1, pp. 257-265, 2003.

[34] I. Michałus, D. Chlebna-Sokół, A. Rusińska, E. JakubowskaPietkiewicz, and K. Kulińska-Szukalska, "Evaluation of bone mineral density and bone metabolism in children with multiple bone fractures," Ortopedia Traumatologia Rehabilitacja, vol. 10, no. 6, pp. 602-612, 2008.

[35] H. Peach, J. E. Compston, S. Vedi, and L. W. L. Horton, "Value of plasma calcium, phosphate, and alkaline phosphatase measurements in the diagnosis of histological osteomalacia," Journal of Clinical Pathology, vol. 35, no. 6, pp. 625-630, 1982.

[36] M. A. Chinoy, M. I. Javed, A. Khan, and N. Sadruddin, "Alkaline phosphatase as a screening test for osteomalacia," Journal of Ayub Medical College, Abbottabad, vol. 23, no. 1, pp. 23-25, 2011.

[37] M. C. Backström, T. Kouri, A.-L. Kuusela et al., "Bone isoenzyme of serum alkaline phosphatase and serum inorganic phosphate in metabolic bone disease of prematurity," Acta Paediatrica, vol. 89, no. 7, pp. 867-873, 2000.

[38] A. Goulding, I. E. Jones, R. W. Taylor, S. M. Williams, and P. J. Manning, "Bone mineral density and body composition in boys with distal forearm fractures: a dual-energy X-ray absorptiometry study," Journal of Pediatrics, vol. 139, no. 4, pp. 509-515, 2001.

[39] J.-P. Bonjour, G. Theintz, F. Law, D. Slosman, and R. Rizzoli, "Peak bone mass," Osteoporosis International, vol. 4, no. 1, pp. S7-S13, 1994.

[40] L. K. Bachrach, "Acquisition of optimal bone mass in childhood and adolescence," Trends in Endocrinology and Metabolism, vol. 12, no. 1, pp. 22-28, 2001.

[41] I. Ghaly, F. H. Hussein, S. Abdelghaffar, G. Anwar, and R. M. Seirvogel, "Optimal age of sexual maturation in Egyptian children," Eastern Mediterranean Health Journal, vol. 14, no. 6, pp. 1391-1399, 2008. 


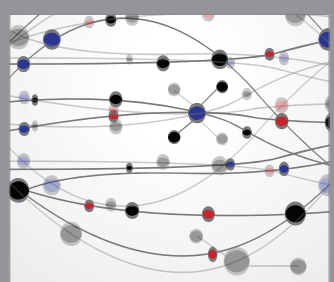

The Scientific World Journal
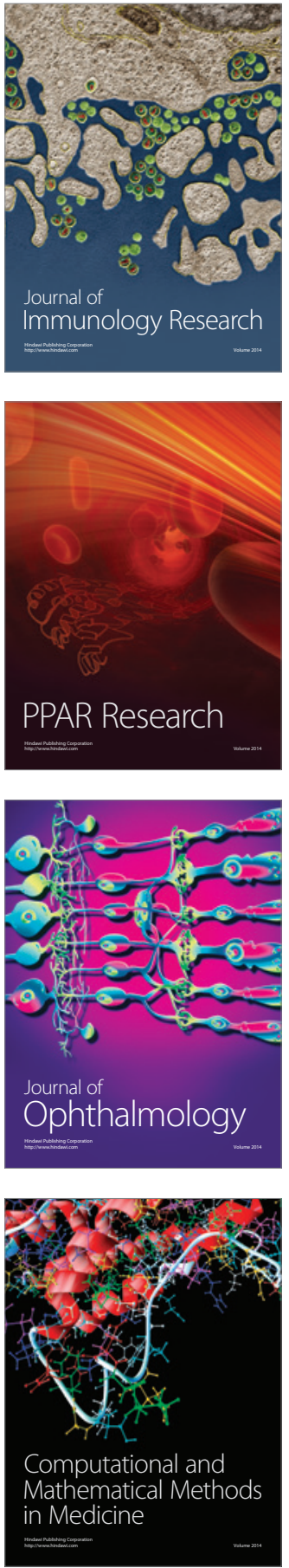

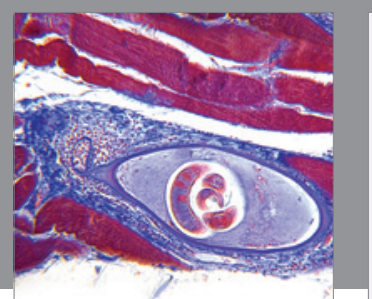

Gastroenterology Research and Practice

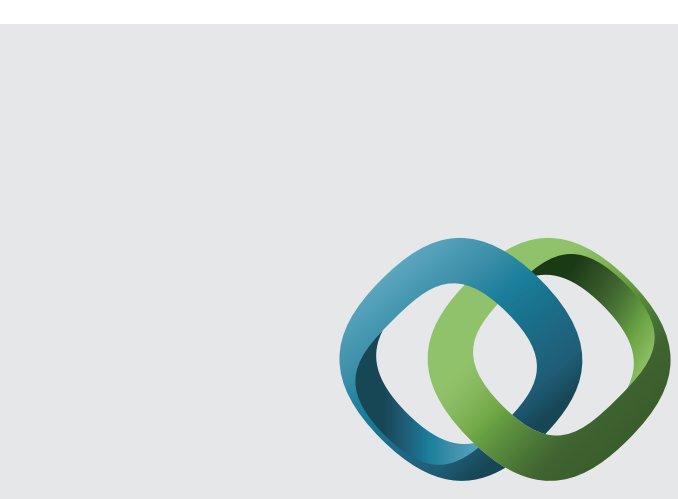

\section{Hindawi}

Submit your manuscripts at

http://www.hindawi.com
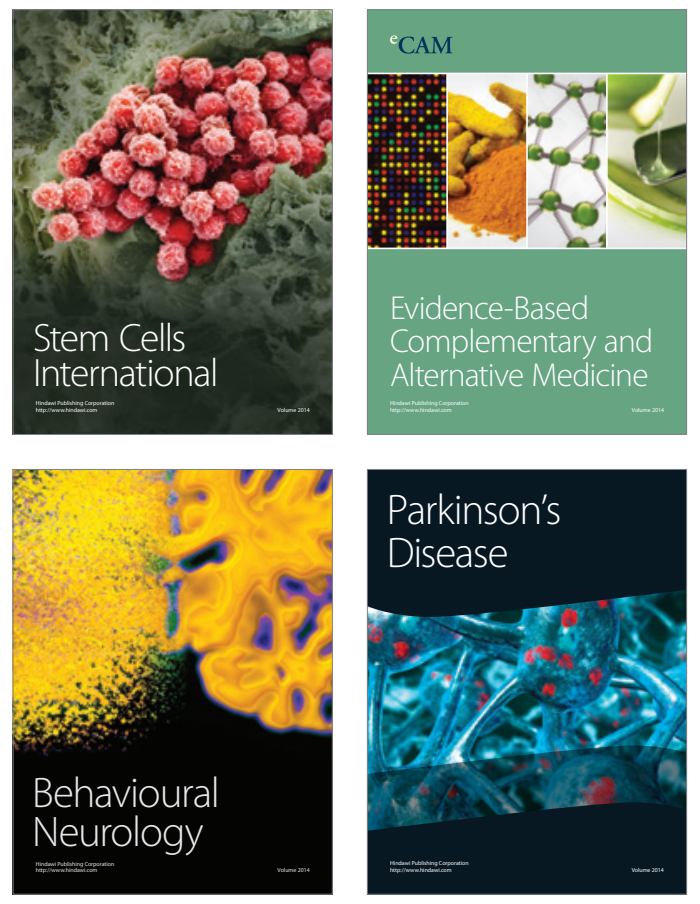
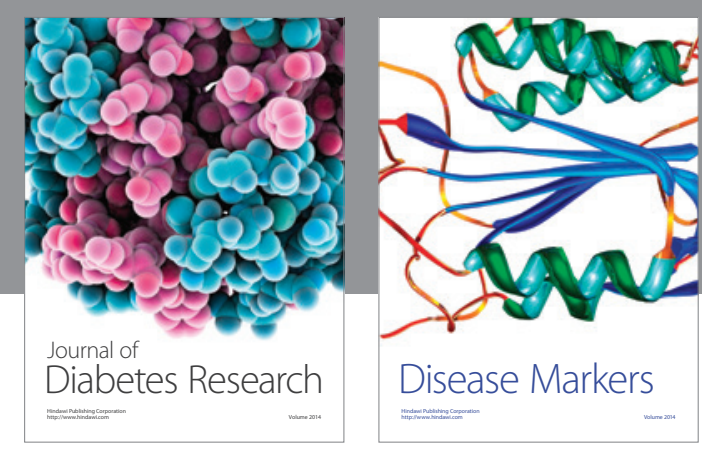

Disease Markers
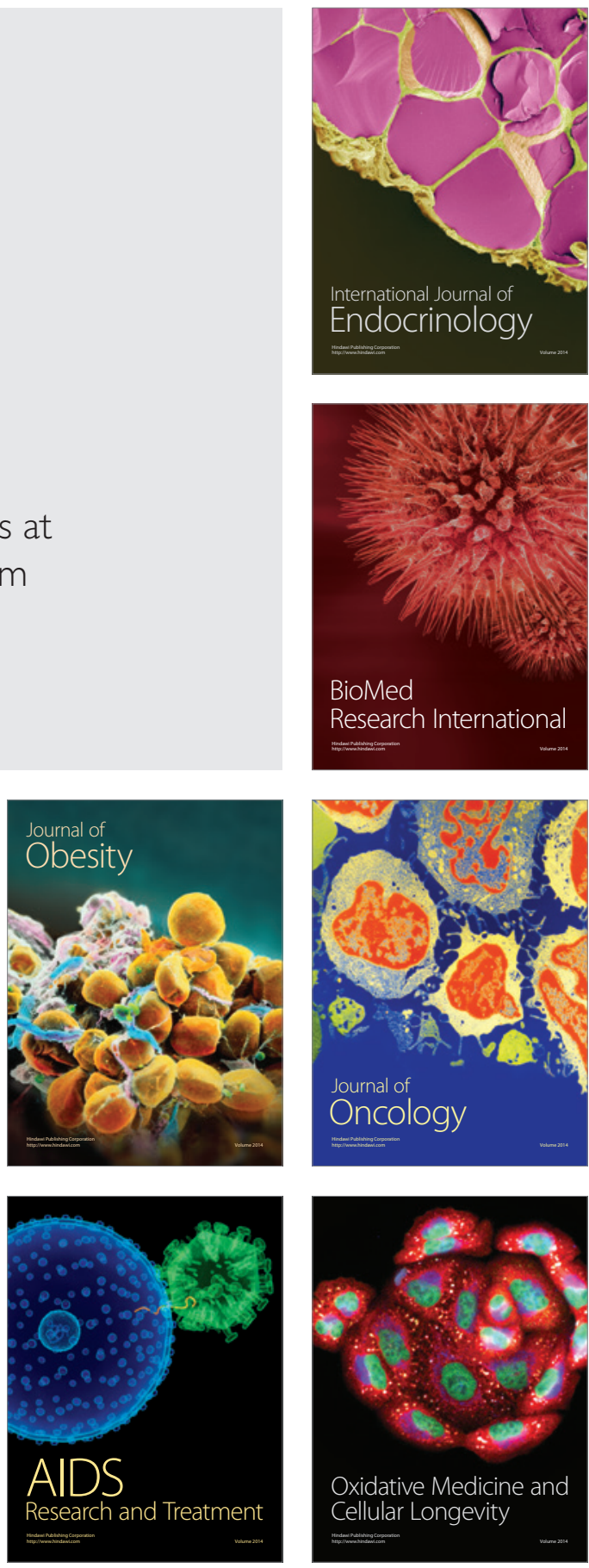